
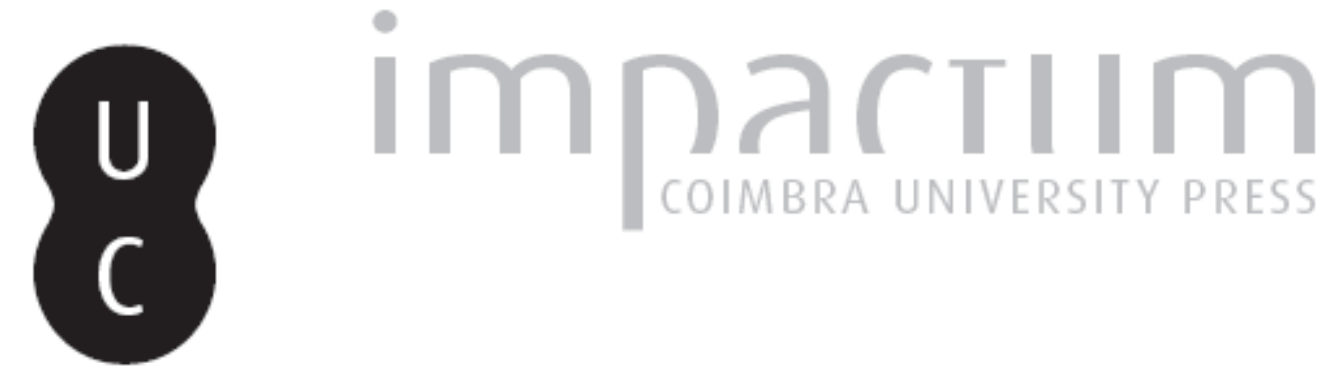

\title{
As competências linguísticas de Fernão Mendes Pinto e o seu uso do malaio
}

Autor(es): Thomaz, Luís Filipe

Publicado por: Faculdade de Letras da Universidade de Coimbra

URL persistente:

URI:http://hdl.handle.net/10316.2/32760

DOI:

DOI:http://dx.doi.org/10.14195/0870-4112_7_13

Accessed : $\quad$ 26-Apr-2023 11:26:01

A navegação consulta e descarregamento dos títulos inseridos nas Bibliotecas Digitais UC Digitalis, UC Pombalina e UC Impactum, pressupõem a aceitação plena e sem reservas dos Termos e Condições de Uso destas Bibliotecas Digitais, disponíveis em https://digitalis.uc.pt/pt-pt/termos.

Conforme exposto nos referidos Termos e Condições de Uso, o descarregamento de títulos de acesso restrito requer uma licença válida de autorização devendo o utilizador aceder ao(s) documento(s) a partir de um endereço de IP da instituição detentora da supramencionada licença.

Ao utilizador é apenas permitido o descarregamento para uso pessoal, pelo que o emprego do(s) título(s) descarregado(s) para outro fim, designadamente comercial, carece de autorização do respetivo autor ou editor da obra.

Na medida em que todas as obras da UC Digitalis se encontram protegidas pelo Código do Direito de Autor e Direitos Conexos e demais legislação aplicável, toda a cópia, parcial ou total, deste documento, nos casos em que é legalmente admitida, deverá conter ou fazer-se acompanhar por este aviso.

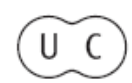




\section{Sociedade em Tumulto}

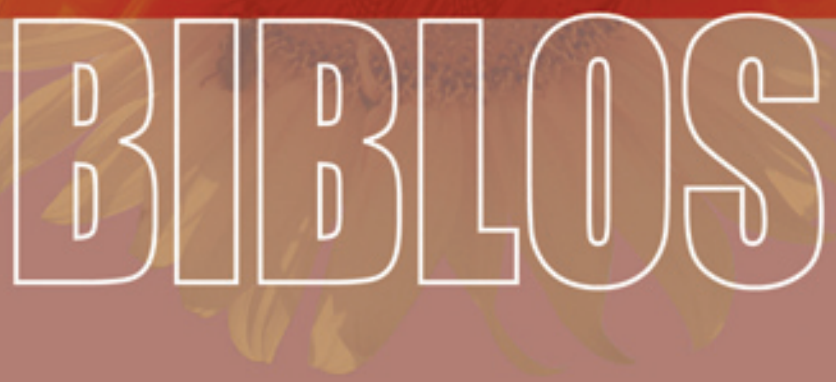

REVISTA DA FACULDADE DE LETRAS

UNIVERSIDADE DE GOIMBRA 
Biblos, n. s. VII (2009) 295-322

Luís Filipe Thomaz

Universidade Católica Portuguesa

\section{AS COMPETÊNCIAS LINGÜÍSTICAS DE FERNÃO MENDES PINTO E O SEU USO DO MALAIO}

\section{Resumo}

Fernão Mendes Pinto prima por um estilo impressionista ante litteram, de modo que a impressão que o seu leitor colhe é verosímil nos seus traços gerais, ainda que cada pormenor que fornece não seja necessariamente verídico. Um dos processos de que se serve para inculcar a dupla impressão de exotismo e autenticidade que pretende transmitir é dar a cada lugar, a cada pessoa e a cada coisa um nome, preocupação que o torna um precursor do verismo do século XIX. Seria inteiramente impossível que, no momento em que redigiu a Peregrinação, vinte ou trinta anos após as aventuras que narra, se recordasse de tamanha cópia de pormenores, pelo que é de assumir a priori que bastas vezes tenha recorrido à invenção. A análise lingüística dos nomes que fornece confirma plenamente essa presunção: resulta claro que tinha certos conhecimentos de malaio, língua de comércio dos mares do Arquipélago até ao sul da China, e é a ele que recorre para dar nome aos seus bois (por vezes correcto, por vezes verosímil, mas outras manifestamente erróneo), quer dentro da zona em que o malaio era utilizado quer mesmo fora dela.

Palavras-chave: Fernão Mendes Pinto, Peregrinação, literatura portuguesa de viagens, malaio, línguas orientais.

\section{Abstract}

Fernão Mendes Pinto uses a kind of impressionistic style that gives his reader an overall credible picture, although the details that he provides are not necessarily accurate. As his aim is to convey, at the same time, an impression of exoticism and authenticity, he always gives a name to each person, place or thing. Since his book Peregrination was written some 20 or 30 years after his adventures in the East, he obviously could not remember such a great number of names, and therefore it can be assumed that he was often led to invent them. The linguistic analysis of the names he uses confirms that he had some notions of Malay (which was used as vehicular language for commerce in the area 
from the seas of the Archipelago to the South China shores), and he resorts to it in creating names within the Malay World as well as outside of it.

Keywords: Fernão Mendes Pinto, Peregrination, Malay, Oriental languages, Portuguese travelogues. Keywords: tragic actor, metaphor, representation.

Por muitas e variadas razões, que não cabe aqui esmiuçar, a Peregrinação de Fernão Mendes Pinto é, desde a sua publicação em 1614, uma das mais célebres obras da literatura portuguesa; é, ao lado de Os Lusíadas e dos Trabalhos de Jesus de Frei Tomé de Jesus uma das três obras portugueses mais traduzidas em idiomas estrangeiros.

Um dos fatores que contribuiu para a sua celebridade foi, sem dúvida, a originalidade do seu estilo ímpar, que a situa entre a literatura de viagens, o romance picaresco e a novela filosófica; mas é exatamente esse caráter híbrido o que mais dificulta a sua interpretação em termos rigorosamente históricos. De facto, nem aqueles que têm tratado a sua obra como texto meramente literário, como se não contivesse qualquer referência ao mundo real, nem os que se obstinaram a descortinarlhe um fundamento objetivo por detrás de cada facto ou alusão que contém nos conseguiram até aqui oferecer uma visão satisfatória da sua polivalência. A jornada de Fernão Mendes Pinto é, com efeito, a um tempo uma viagem pelo espaço geográfico, mais concretamente pelos mares do Extremo Oriente, e uma peregrinação interior, em busca de si mesmo e duma verdade imóvel, transcendente, que paira muito acima da multidão de gentes, crenças e culturas que, em vórtice estonteante, perpassa pelas suas páginas. Essa peregrinação interior culmina nos capítulos finais da obra no encontro com Francisco Xavier, que assim ocupa, sem rigoroso respeito pela ordem cronológica dos acontecimentos, uma posição cimeira, constituindo no itinerário mental de Mendes Pinto como que uma meta.

Não se pode perder de vista o caráter compósito da Peregrinação e a radical ambiguiidade do seu género literário ao abordar o problema dos conhecimentos linguiísticos do seu autor. Há, pois, que atacá-lo com a certeza prévia de que a sua resolução nos não fornecerá por si só a chave do velho enigma, belamente expresso no jogo de palavras "Fernão, mentes? minto...".

$\mathrm{Na}$ ausência de documentação fidedigna que nos permita seguir a pari passu as andanças de Fernão Mendes pelas terras e mares do Oriente, a análise linguística da sua obra, tal como a análise geográfica ou etnológica, apenas nos permitirá distinguir o possível ou 
verosímil do impossível e, por conseguinte, irreal, mas não o real do imaginário. Para mais, entre estes dois polos situa-se uma espécie de cone da penumbra, em que o vivido se interpenetra com o ouvido e as recordações esfumadas pelo correr dos anos se misturam ao desejo de tornar presente um passado já volvido, que apenas a imaginação permite aviventar. É também nessa zona cinzenta que se situam as aventuras, quiçá bem reais, que o autor escutou da boca de outrem mas transmite num registo íntimo, de que apenas o uso da primeira pessoa do singular é abonado garante. Essa técnica narrativa está longe de ser original. Deixando de lado casos extremos, como o das Viagens de João de Mandeville, mero centão de excertos de outros itinerários, em parte míticos, em parte autênticos, achamo-la, por exemplo, alguns decénios antes de Mendes Pinto, nas páginas de Ludovico de Varthema, em que a crítica histórica consegue sem dificuldade destrinçar uma viagem real, pelo Levante até à Índia e às voltas pelo Malabar, de duas imaginárias, uma à Pérsia outra à Insulíndia, em que o autor narra o melhor que pode como sendo seu o que escutou de boca alheia. Para o viajante bolonhês, como para o nosso autor, parece vigorar como ideal a máxima si non é ver'é ben' trovato; daí que as preferências de ambos pareçam ir para o plus beau que nature.

A análise da cronologia da Peregrinação, combinada ao conhecimento dos ventos e monções propícios a cada navegação, permite concluir com segurança que de nem todas as aventuras que narra pode ter sido Fernão Mendes o sujeito, sem todavia nos deixar discernir ao certo as que escutou das que viveu realmente. É aí que a análise lingüística nos pode fornecer uma achega, como veremos a seguir.

A importância que na Peregrinação têm o discurso e o diálogo não se relaciona tanto com a sua vertente de livro de viagens como com a sua faceta de novela filosófica. É esta que exige que as personagens que põe em cena declarem ao leitor as suas intenções e o tomem por confidente nos seus comentários aos factos, já que é pela boca delas que o autorfilósofo se exprime; é uma técnica de narração que remonta pelo menos a Tucídides, em cuja Guerra do Peloponeso avultam, entre outros, o célebre discurso dos Mélios, no livro V, por cujo conduto discorre o autor sobre a dramática oposição entre desejo de liberdade e vontade de poder. Tal técnica narrativa implica que o ego quasi-omnipresente que na Peregrinação fala ao leitor entenda onde quer que esteja o que se diz, e, sem as mais das vezes se servir de intérpretes, dialogue em qualquer país com quantos cruza. 
Outro aspecto que na Peregrinação salta à vista é a abundância não só de topónimos, etnónimos e antropónimos, mas também de substantivos concretos de origem mais ou menos asiática, que servem ao autor para designar pessoas e cousas, cargos, instituições e ideias estranhos ao universo cultural do português médio a que a obra se destina. Essa superabundância de nomenclatura fornece, por assim dizer, um atestado de veracidade ao relato, em que cada cousa é real e tem um nome, provando, como nos autos de corpo de delito, que "tudo se passou na verdade, como acima escrito fica". É processo narrativo já comum no Antigo Testamento, mormente nos livros proféticos, em que, como notou já $\mathrm{S}$. Gregório Magno, serve para asseverar a veracidade das visões narradas pelo profeta. Eis o seu comentário ao capítulo I de Ezequiel, em que este descreve a visão da glória divina que teve nas margens do Cobar, durante o seu exílio em Babilónia:

Costume é do discurso profético que primeiro se descreva a pessoa, o tempo e o lugar, e só depois se comecem a dizer os mistérios da profecia; e que, para mais solidamente mostrar a verdade, primeiro se fixe a raiz e depois, por meio de sinais e alegorias, se profiram os frutos do espírito. Por isso Ezequiel indica o tempo de sua idade, dizendo "e aconteceu no trigésimo ano, no quarto mês, no dia quinto do mês". E especificando o lugar, ajunta: "como estivesse entre os cativos, junto ao rio Cobar, se abriram os céus e eu vi visões de Deus". E insinua o momento, explicando: "no dia quinto do mês". Trata-se do quinto ano após a transmigração do rei Joaquim. E para melhor indicar a pessoa, refere também a família, ũa explicar: "fez-se a palavra do Senhor a Ezequiel, filho de Buzi, sacerdote".

Mas a vontade obsessiva de concretizar, que de cabo a rabo percorre as páginas da Peregrinação parece ter, simultaneamente, um outro escopo ainda: contribuir para o tópico que João David Pinto Correia designou por exotema, ou seja, um conjunto de alusões que conduzem o leitor a um mundo exótico, que não só é diferente do seu como o leva a pôr este em causa ou, pelo menos, a relativizá-lo. Só então queda aberto o acesso àquela verdade superior e transcendente que o autor quer que entrevejamos. Se nos é permitido criar mais um neologismo, designaríamos, semelhantemente, aquela outra figura de estilo, de escopo asseverativo, bastas vezes combinada a esta, por aletema (do grego alêthês, "verdadeiro") já que o seu objectivo é induzir o leitor a crer que é verdade, até ao mínimo pormenor, tudo quanto relata. É assim 
que, por exemplo, no capítulo 59, põe na boca do corsário guzerate Coja Acém (o que pode corresponder ao persa $K h^{w}$ âjè Hasan, senão a $K h^{w}$ âjè Husain), a shahâda ou profissão de fé muçulmana, lâ ilâh $h^{a} i l l a \hat{-}$ 'Llâh $h^{a}$, Muhammad ${ }^{u n}$ rasûl $^{u}$-'Llâh ${ }^{i}$, "não há mais deus senão Deus, Mafamede é o enviado de Deus":

O perro do Coja Acem, que até este tempo não era ainda conhecido, acudio com muita pressa ao desmancho que via nos seus, armado com uma coura de lâminas de citim cramesim franjada d'ouro que fora de Portugueses, e bradando alto para que todos o ouvissem, disse por três vezes lah ilah hilah lah, Muhamed roçol halah! Ó massoleimões e homens justos da santa lei de Mafamede, como vos deixais vencer assi de üa gente tão fraca como são estes cães, sem mais ânimo que de galinhas brancas e de molheres barbadas?

Nalguns casos o recurso ao exotema-aletema leva ao uso de citações e empréstimos vocabulares fora do seu correto contexto geográfico e lingüístico: é o que se passa, por exemplo, no capítulo 95 da Peregrinação, em que Fernão Mendes atribui a um antigo imperador da China, que teria reinado por volta de 528 da nossa era o nome de Crisnagol Dacotai, de consonância tâmul; pelo menos a primeira parte do nome, Crisna, i. e., Kṛşna, que nada tem de chinês, é facilmente identificável e remete-nos indubitavelmente para a Índia. Noutros casos, porém, o recurso ao exotema-aletema conduz à pura invenção lingüística; tal é, por exemplo, o caso do capítulo 122 da Peregrinação, em que, interrogados pelo rei dos Tártaros sobre a sua origem e sobre a distância a que ficava de Pequim a sua pátria, os companheiros de Mendes Pinto respondem que são de Portugal, a uns três anos de viagem daquelas partes. Então o rei,

...batendo três vezes na coxa com ũa varinha que tinha na mão e os olhos postos no Céo como que dava graças a Deos, disse alto, que todos o ouviram: Julicavão, julicavão, minaydotoreu pisinão himacor davulquitaroo xinapoco nifando hoperau vuxido vultanitirau companoo foragrem hupuchiday purpuponi hincau, que quer dizer: "ó criador, ó criador de todas as cousas, qual de nós outros, pobres formigas da terra, poderá comprender as maravilhas da tua grandeza?".

A frase citada não faz, evidentemente, sentido em nenhuma língua conhecida; mas afiança que é autêntica, ipsissimis verbis, a máxima 
teológica que em seguida, afetando tratar-se de mera tradução, se enuncia, para cuja solenidade ficara o leitor desde logo preparado. Um pouco mais abaixo, novo exotema lingüístico introduz nova reflexão filosófica: sem querer crer no que escutara, el-rei, "que não tinha esta máquina do mundo por tamanha", insiste em que lhe precisem o tempo de jornada que separa da sua a terra daquela estranha gente:

...e acenando com a mão, nos fez chegar até os primeiros degraos da tribuna onde os quatorze reis estavam assentados, e nos tornou a preguntar como homem espantado do que tinha ouvido: pucau, pucau?, que quer dizer, "quanto, quanto?" - a que respondemos o mesmo de antes.

O soberano tártaro pode então retirar a sua conclusão, que aparentemente constitui o cerne da mensagem a transmitir ao leitor:

Conquistar esta gente terra tão alongada de sua pátria dá claramente a entender que deve de haver entre eles muita cubiça e pouca justiça.

Desta vez a máxima é ainda sublinhada pelo comentário que lhe tece um velho, chamado Raja Benão, que assistia ao rei:

Assi parece que deve ser, porque homens que por indústria e engenho voam por cima das águas todas por aquirirem o que Deos lhes não deu, ou a pobreza neles é tanta que de todo lhes faz esquecer a sua pátria, ou a vaidade e a cegueira que lhes causa a sua cobiça é tamanha que por ela negam a Deos e a seus pais.

No capítulo 73 Fernão Mendes Pinto pretende mesmo reproduzir fielmente quatro frases ditas por gente bárbara e disforme "em língua mui desentoada", que nenhum dos circunstantes pôde compreender: quiteu parão fau fau, pur pacam pochi pilaca hunangue doreu, etc. Como seria de esperar, não há neste caso tradução; mas a citação do discurso ininteligível serve para atestar a veracidade da existência dos gigauhos, espécie de faunos que viveriam, entre os mais diversos animais selváticos, em certa montanha da China.

No entanto, não é sempre por invenção lingüística que se consegue o efeito de exotema. Por vezes consegue-se simplesmente pelo recurso à citação inconfessada: assim no capítulo $4^{\circ}$, de vários pontos de vista paradigmático, em que o autor relata sucintamente uma viagem que teria feito à Etiópia. Aí nos conta como, a partir de Arquico, na Eritreia, 
se internou em território etíope para encontrar a princesa Tigramahom, mãe do Preste João, vindo a dormir certa noite em "ũas casas grandes que se diziam Betenigus, que quer dizer 'casas de rei' ". Beta negus quer, de facto, dizer "casa do rei" em ge 'ez ou etiópico litúrgico, língua que Fernão Mendes manifestamente ignorava; é certamente da Verdadeira Informação das Terras do Preste João, do Padre Francisco Álvares, capítulo XVIII, que retira a informação. Aí se lê com efeito: "Este lugar é cabeça da terra e reino do Barnagais, em que estão seus paços principais a que eles chamam betenegus, que quere dizer casa delRei”. Quanto ao nome da princesa, Tigramahom, a fonte é sem dúvida a mesma, capítulos XXXIV e seguintes; apenas há a notar que o termo - que em formas assaz vizinhas reaparece mais tarde nas páginas dos jesuítas Manuel de Almeida e Manuel Barradas - não é nome, mas sim título, transcrevendo Tegrê makwannen, que significa "governador do Tigré" (a província etíope sobranceira à Eritreia, em que se situa Axum, a antiga capital). Aplica-se, por isso, em regra a um homem e não a uma mulher. Seja como for, no capítulo 225 aparece-nos, ao invés, como topónimo: "as serras de Tigremahom". Fernão Mendes fala-nos em seguida de oqueás de ouro usadas como dinheiro, explicando que vale cada oqueá doze cruzados; a fonte é desta feita o capítulo XXVIII de Francisco Álvares, em que se lê "em todos os reinos do Preste João não corre moeda, senão ouro a peso, e o principal peso se chama ouquia, que é uma onça e faz em peso dez cruzados". O termo transcreve o etiópico waqêt, ou quiçá antes o seu étimo arábico waqiyya, derivado do latim uncia, "onça".

Seja como for, esgotado o arsenal que lhe fornecia a Verdadeira Informação, Fernão Mendes Pinto fora entretanto recorrendo à sua ampla capacidade inventiva, para dar aos noviços dos mosteiros etiópicos um nome supostamente local, santileus - quando na realidade o noviço se designa por haddis takl ou, mais classicamente, por takl haddis, literalmente, "planta nova" ${ }^{1}$. Inventado igualmente parece o título de ticaxi, que atribui ao capitão da região, que diz terlhes facultado montadas; a não ser que tenha transformado em título o nome do rio Takkaze, que de facto atravessa a zona, separando o Tigré do Bagameder.

${ }^{1}$ Takl haddis é a forma correta em ge 'ez ou etiópico clássico, língua em que o determinado precede o determinante; haddis takl é forma influenciada pela sintaxe do amárico, em que - caso único entre as línguas semíticas - a ordem das palavras é inversa. 
Nesta curta seqüência topamos assim com pelo menos três processos de criação de exotemas vocabulares, supostos em qualquer caso conferir a côr local: o uso correto de préstamos lexicais, aprendidos pelo uso oral ou através de textos (casos de betenegus e ouquiá), o emprego de termos exóticos em sentido impróprio (caso de Tigremahom, e talvez também de ticaxi), e o recurso à invenção (caso de santileu).

Como vamos ver a língua-fonte a que, as mais das vezes, recorre Fernão Mendes é o malaio. Este fornece-lhe uma série de empréstimos vocabulares corretos, uns de uso corrente entre os nossos escritores quinhentistas, outros mais raros, roçando por vezes pelo happax. Estão no primeiro caso termos como ourobalão (hulubalang em malaio), "capitão, chefe militar, guerreiro de escol" e amboraja ou amborraja (em malaio hamba raja), "escravo do ${ }^{2}$ rei, vassalo direto do sultão", que Mendes Pinto utiliza para descrever personagens com que topou na corte do rei dos Batas (Batak) no norte de Samatra, a que fora enviado como embaixador por Pero de Faria, capitão de Malaca. No segundo caso está a locução à charachina (em malaio cara cina", "maneira china"), expressão cara ao nosso autor, que a emprega pelo menos meia dúzia de vezes na sua obra mas que, salvo falha de memória, jamais achámos nas páginas de outro escritor; num outro contexto (cap. 201) o nosso autor emprega analogamente chara japão, i. e., cara jepun, "à moda japoa, à maneira do Japão". Semelhante é o caso de gregoge (do malaio gergaji, "serra"), outro happax que o autor utiliza para designar o suplício que consiste em serrar às postas um condenado.

O malaio fornece-lhe também um arsenal de palavras a utilizar a despropósito, como o título de Rajá Dato que confere ao 'moulana maior' da cidade de Medina. Raja, "rei" é um termo de uso corrente usurpado pelo malaio ao sânscrito (râjâ), mas, evidentemente, desconhecido na Arábia, e dato, datu ou datuk (ou ainda, à javanesa, ratu) um termo de respeito que se encontra em quase todas as línguas autronésicas, cujo

${ }^{2}$ Note-se que em malaio o genitivo se exprime por mera justaposição, não havendo, pois, elemento correspondente ao português $d e$.

${ }^{3}$ Note-se de uma vez para sempre que na éjaan baru ou "nova ortografia" do malaio-indonésio, adoptada em 1972 poelos quatro países que o têm por língua oficial (Indonésia, Malásia, Singapura e Brunei), tal como na transcrição do sânscrito, a letra $c$ nota uma africada palatal ou pré-palatal surda idêntica ao $c h$ transmontano ou castelhano $(=t x)$. Quando não marcado com acento $(\hat{e})$ - o que apenas se faz em obras didácticas, mas adoptámos também aqui - o $e$ (dito nesse caso $e$ pepet) soa sempre como o e mudo em português.

Faculdade de Letras | Universidade de Coimbra 
significado original é quiçá o de "avô", ainda em uso em malaio, embora as mais das vezes se empregue antes para designar um nobre, um chefe ou um profissional especializado, como um curandeiro. Já moulana é termo comum ao malaio, ao persa, ao hindustani e ao arábico, de que provém, em que maulânâ, significa "nosso mestre" (maulâ, da raiz waliya, "estar próximo", apelativo usado para os mestres espirituais, em especial os das confrarias sufis - de onde mulá, bastas vezes erroneamente grafado mullah - com o sufixo possessivo -nâ, que indica a $1^{a}$ pessoa do plural); embora mais usado em meios xiitas ou sufis, na Índia, no Irão e na Insulíndia, não é impossível que se desse em Medina a qualquer dignitário religioso.

Neste caso, como em muitos outros, o despropósito é meramente geográfico. Teremos ocasião de observar como tal caso é corrente, já que é o de numerosos topónimos estranhos ao mundo malaio, como por exemplo Bralapisão, no Camboja, que parece transcrever berhala pisang, "ídolo-banana" ou "ídolo das bananas", quiçá no sentido "templo idólatra das bananeiras"; é também o de numerosos antropónimos, como o Raja Benão com que topamos já, aparentemente transcrição de raja benang, "rei das linhas de coser", ou, com um homónimo, "rei das alforrecas", o de Quiai Panjão (Kiai Panjang, "Mestre Longo, Senhor Comprido"); e aindo o de alguns teónimos, como Quiai Ujão, que seria na China o deus da chuva, do malaio kiyahi ou kiai, "mestre, senhor" e hujan, "chuva". O título de quiai é um dos exotismos vocabulares da predileção do nosso autor, que o confere não só a personagens terrestres mas também a divindades, tanto na China, como na Birmânia e quiçá alhures. Se ali temos Quiai Ujão, aqui topamos com Quai Adocá, deus do trovão; e em ambos os países encontramos Quiai Nivandel, "deus das batalhas do campo Vitau".

Noutros casos o despropósito não é geográfico, mas temático, como sucede com caquesseitão, nome que o autor dá a uma espécie de enorme palmípede carnívoro que existiria nos rios de Samatra, descrito em pormenor no capítulo 14 da Peregrinação, que parece transcrever simplesmente o malaio kaki saitan, "pés de Satanás".

O vocabulário malaio parece servir também a Fernão Mendes para criar palavras, juntando elementos que existem de per si para formar compostos inexistentes. Tal deve ser o caso de alguns dos antropónimos a que aludimos (cujo sentido é por vezes absurdo, como sucede com Raja Benão) e, provavelmente, o de numerosos topónimos que fazem sentido mas não se encontram nem nos textos nem na cartografia, como o estreito de Minhagaru, no norte de Samatra (minyak, "óleo" de 
gaharu, "águila ou calambuco, Aquilaria malaccensis, Lam."), a ilha de Pulo Capás, junto à costa do Hainão (pulau kapas, "ilha do algodão"), as de Pulo Hinhor (pulau nyiur, "ilha dos cocos ou dos coqueiros" ${ }^{4}$ ) e Pulo Camude (pulau kemudi, "ilha do leme") na costa de Tanaçarim, etc. Neste particular há que notar, contudo, que, sendo o malaio a língua do comércio não só no Arquipélago Asiático mas também ao longo das costas do Mar da China Meridional, alguns acidentes geográficos, como Pulo Condor, na costa vietnamita, conservaram até hoje os nomes malaios que lhes deram os pilotos de antanho; é, por isso, difícil determinar onde termina uma toponímia caída em desuso e onde principia a imaginação de Fernão Mendes Pinto.

O malaio é uma língua do grupo austronésico, como as suas irmãs de tipo aglutinante, em que a uma base ou radical geralmente dissilábico se podem juntar prefixos, infixos e sufixos para formar novos vocábulos. É idioma originário das planícies da costa oriental de Samatra e ilhas adjacentes, por isso ditas tradicionalmente Tanah Melayu, "terras malaias, país malaio"; as suas maiores afinidades são com as línguas vizinhas, em particular com o menancabo ou minangkabau, falado nas terras altas contíguas a oeste e noroeste. Foi daí que, em época impossível de precisar, irradiou para a península de Malaca, em cujo interior subsistem ainda hoje importantes grupos aborígenes (ditos orang asli, "gente original"), que falam línguas da família austro-asiática ou mon-khmer. Irradiou também para as costas de Bornéu, sem que se saiba ao certo em que medida essa difusão foi simplesmente fruto do comércio e em que medida correspondeu a uma real transmigração de populações. Seja como for o banjar - o dialecto malaio falado ao longo da costa meridional de Bornéu - conserva alguns traços arcaizantes que mostram que aí se fixou de longa data.

$\mathrm{Na}$ época histórica a distribuição geográfica do malaio em torno dos estreitos de Malaca e Carimata lembra assim a do grego antigo em torno do Mar Egeu. Como os gregos de antanho, os malaios aparecem ao longo

${ }^{4}$ F. M. P. conhecia certamente o malaio falado em Malaca, o dialecto de Johor - Riau sobre que se baseava a antiga ortografia da Malásia, em que as vogais são geralmente abertas, sem embargo da metafonia ou harmonia vocálica, ao passo que a éjaan baru se baseia na pronúncia mais corrente na Indonésia e no norte da Malásia, em que quando na primeira sílaba há uma vogal fechada ( $i$ ou $u$ ) a vogal da segunda, se é uma sílaba "fechada" (i.e., terminada em consoante) tem, em princípio, também um timbre fechado. Termos como nyior, timor, puteh, etc. correspondem à pronúncia de Johor - Riau, e grafam-se hoje oficialmente nyiur, timur, putih, etc., 
da história como um povo de nautas e mercadores; como a civilização grega da Antiguidade, a civilização malaia tem um "centro oco", isto é, não se estende por um espaço geográfico compacto e definido, centrado numa cidade capital, antes se dispondo em torno de um mar mediterrâneo, o Egeu no caso grego, o mar entre Samatra, Java, Bornéu e a Península de Malaca no caso malaio. Os estabelecimentos malaios dispersos pelas costas ocidental e meridional de Bornéu, sobretudo na foz dos grandes rios e na confluência destes com os seus principais afluentes, permitiam aos malaios controlar o acesso ao interior da ilha e, por conseguinte, a quase totalidade do comércio de médio e longo curso, que em tais plagas equatoriais, cobertas de selva densa, se faz necessariamente por via fluvial. Os malaios desempenhavam assim na região um papel semelhante ao que fenícios, gregos e cartagineses desempenharam no Mediterrâneo antes da unificação romana: compravam às populações do interior, com que mantinham laços de vizinhança, os seus produtos e vendiam-lhes os que importavam de outras partes, obtidos através de malaios de outros estabelecimentos, a que os ligava uma solidariedade étnica, lingüística e religiosa, que por sua vez os obtinham das gentes dos seus sertões.

Os mais antigos documentos escritos em malaio são três inscrições de finais do século VII, provenientes duas delas dos arredores de Palimbão (Palembang) e a terceira da ilha de Banca (Bangka), que fica quase defronte. Foi, com efeito, na zona de Palimbão que se sediou o primeiro grande império da Insulíndia, o de Çrî Vijaya ou Seri Wijaya, que, dominando os estreitos de Malaca e Sunda por que o Índico comunica com o Pacífico, exerceu do século VII ao XII uma verdadeira talassocracia no Arquipélago. Essas três inscrições mostram que a despeito da língua de religião e de cultura ser aí, como nos demais estados indianizados da Ásia do Sueste, o sânscrito, a língua do povo era o malaio.

Graças ao controle que por intermédio dos seus corsários exercia sobre os estreitos de Sunda e de Malaca, única passagem entre o Índico e os mares do Arquipélago e da China, o reino de Seri Wijaya tornouse rapidamente na grande potência marítima da região, e a sua capital em rico empório de comércio. Foi certamente por tal motivo que a sua língua, o malaio, se veio a tornar em língua de comércio através da Insulíndia, até ao Mar da China.

Importante testemunho da sua difusão foi o achado de uma inscrição escrita em malaio em Gandasuli, perto de Kedu, em Java Central, datada de 832 A. D. Há algum tempo foi também descoberta 
junto à Laguna de Bay, perto de Manila, nas Filipinas, uma inscrição em antigo malaio, datada de 900 A. D. ${ }^{5}$. Por outro lado um recente estudo dos empréstimos vocabulares malaios no tagalo, língua falado na zona central de Lução ${ }^{6}$, veio demonstrar que esses vocábulos foram importados numa época muito antiga, pois preservam - nomeadamente os de origem sanscrítica - traços fonéticos arcaizantes, que desapareceram do malaio moderno. Estes factos vêm provar que o malaio foi utilizado como língua de comércio na Insulíndia oriental desde o período de Seri Wijaya. No século XV a hegemonia de um outro reino de língua malaia, o sultanado de Malaca, fundado em 1403 e convertido em 1414 ao islão, mais deve ter contribuído para reforçar a sua posição.

O uso do malaio como língua veicular e de comércio estendeu-se até à costa meridional da China. É por isso que ainda hoje se dão em Macau nomes malaios aos pesos e medidas em uso no Celeste Império, como sejam tael (tahil em malaio, em cantonês kân), cate (kati em malaio, leong em cantonês), pico (pikul em malaio, tám em cantonês), etc. É pelo mesmo motivo que, como adiantámos já, diversos acidentes da costa indochinesa conservaram praticamente até aos nossos dias os seus nomes malaios: além da referida ilha de Pulo Condor pulau, "ilha" e kundur, "cambalenga, jerimum, espécie de abóbora, Benincasa hispida, (Thunb.) Cogn.”, a $8^{\circ} 40^{\prime} \mathrm{N}, 105^{\circ} 55^{\prime} \mathrm{E}$, ao largo do delta do Mecom, dita Con Son em vietnamita - existe a de Pulo Obi (provavelmente Pulau Ubi, "ilha dos inhames") a sul da Ponta de Camboja, em vietnamita Hon Khoai, o Cabo Varela (berhala, "ídolo"), a $12^{\circ} 55^{\prime} \mathrm{N}, 109^{\circ} 24^{\prime} \mathrm{E}$, ponto mais oriental da costa anamita, o Cabo Batangan ("cabo do tronco"), umas 150 milhas mais ao norte, a $11^{\circ} 2^{\text {' }}$ $\mathrm{N}, 109^{\circ} \mathrm{E}$, etc.

Foi provavelmente do uso intensivo do malaio como língua veicular que adveio a sua simplificação gramatical, patente sobretudo no reduzido número de afixos que mantém em uso: apenas 42 , contando todas as combinações possíveis, contra 79 no menancabo, assaz vizinho, e mais ainda em tagalo ou em malgache. A simplificação atinge

${ }^{5}$ vide Anton Postma “The Laguna copper-plate inscription”, Philippine Studies, 40, II, 1992, pp. 183-203. Pode ver-se o texto da inscrição, com tradução em inglês e notas históricas in Paul Michel Munoz, Early Kingdoms of the Indonesian Archipelago and the Malay Peninsula, Éditions Didier Miller, Singapura, 2006, pp. 236-239.

${ }^{6}$ K. A. Adelaar, "Malay and Javanese Loan-words in Malgasy, Tagalog and Siraya (Formosa)", in Bijdragen tot de Taal-, Land- en Volkenkunde, 150, I (1994), pp. 50-65. 
o extremo no chamado malaio de bazar, em que praticamente se não utilizam afixos, pelo menos conscientemente.

Consideram alguns modernos lingüistas a existência em cada idioma de três possíveis níveis distintos, ainda que sem solução de continuidade: o basileto, ou nível básico de comunicação, que não exige em regra mais de uns 500 vocábulos, em geral completados por modulações de entoação, gestos e outros efeitos extra-lingüísticos de expressão; o mesoleto, que assegura a comunicação lingüística normalmente necessária na vida quotidiana e exige um léxico de cerca de 2.000 vocábulos; e o acroleto, que permite a expressão de todas as subtilezas requeridas pela linguagem jurídica, científica e filosófica e exige um vocabulário muito mais diversificado que, nalgumas línguas mais ricas como o sânscrito pode ir até aos 150.000 vocábulos, embora noutras se fique pelos 20.000 ou pouco mais. Há que notar que nem todas as línguas possuem este nível superior, já que para tais efeitos a tradição cultural impõe muitas vezes o recurso a um idioma diferente, (caso do latim na Europa medieval, do sânscrito na antiga Índia, do persa na Índia muçulmana e na Turquia otomana, etc). Historicamente esse acroleto externo tanto pode representar um substrato como um superstrato ou um adstrato, mas não interessa aqui internarmo-nos por essa via ${ }^{7}$. Basta que digamos que o malaio possuía tradicionalmente os dois primeiros níveis, ao passo que o terceiro, inibido na Idade Média pelo recurso ao sânscrito, após a islamização pelo uso do árabe pelo menos para fins teológicos e litúrgicos, começa timidamente a emergir com textos como o Taj as-Salatin ou Mahkota Raja-Raja ("A Coroa dos Reis") - um tratado filosófico, adaptado do persa em 1603, de muitos pontos de vista comparável ao Leal Conselheiro de D. Duarte para apenas se afirmar decididamente em meados do século XX, após a independência da Indonésia e a da Malásia que elevou as duas principais variantes do malaio ao estatuto de línguas oficiais e do ensino.

Enquanto a linguagem das primeiras crónicas malaias, como a Hikayat Raja-Raja Pasai e a Sejarah Melayu, se situam nitidamente ao nível do mesoleto, o "malaio de bazar" reduz-se, as mais das vezes a um basileto. Era sem dúvida essa variedade simplificada de

${ }^{7}$ Embora sem recorrermos a esta terminologia ocupámo-nos do problema dos três níveis lingüísticos em Timor no artigo "A língua portuguesa em Timor”, in Congresso sobre a situação actual da língua portuguesa no Mundo - Actas, ICALP, Lisboa, 1985, pp. 313-338, reproduzido na nossa colectânea de estudos De Ceuta a Timor, DIFEL, Carnaxide, 1995, pp. 637-665. 
malaio que Fernão Mendes Pinto falava; é curioso notar que entre as numerosas palavras malaias que o seu texto inclui, se não encontram praticamente formas afixadas. É no entanto difícil determinar em que medida era fluente em malaio, mesmo ao nível do basileto, ou se porventura conhecia apenas palavras soltas. Olhando a posteriori a sua obra escrita, esta segunda hipótese parecer-nos-ia mais provável; mas é possível que nos decénios que medeiam entre as suas aventuras e a redação da Peregrinação tenha esquecido muito do que aprendera e que tal impressão seja enganadora. Assim se explicaria que no cap. 158 atribua a Catamás, suposto topónimo do Calaminhão (sito algures na Indochina, provavelmente no país dos Laos), o significado de "camarão de ouro", quando na realidade em malaio ketam mas ou ketam emas significa "caranguejo de ouro".

O nosso autor conhecia indubitavelemente muitos vocábulos malaios para além dos que penetraram mais ou menos no ásio-português da época; é o que explica, por exemplo, a redundância com que topamos no capítulo 151 onde enumera entre os edifícios de Martabão saqueados pelos bramás ou birmanos as "varelas, pagodes e bralas de toda a cidade"; a enumeração repete-se no capítulo 184. Na realidade varela, relativamente comum nos textos da época, e brala, happax de Fernão Mendes Pinto, transcrevem o mesmo termo malaio, berhala, que propriamente significa "ídolo", mas tomou no nosso idioma o sentido de "pagode, templo pagão".

De qualquer modo, se no momento em que redigiu a sua obra Fernão Mendes fosse ainda fluente em malaio, inútil se lhe tornaria inventar frases, como a que põe na boca do rei dos Tártaros, que citámos mais acima, e muitas outras que não fazem sentido em qualquer língua conhecida, em lugar de simplesmente as traduzir em malaio. Mesmo no país dos Batas, onde era certamente nesse idioma que o autor comunicava, aparece-nos uma frase que não corresponde de perto nem de longe nem ao malaio nem ao batak, antes parece simplesmente inventada: pachi parau tinacor, o que vertido em linguagem significaria "ó, quem o visse e logo morresse!". Em malaio poder-se-ia dizer algo como semoga-moga kita lihatnya, selepasnya mati!, o que, mesmo usando outros sinónimos, como mudah-mudahan em vez de semogamoga e o termo mais respeitoso meninggal em lugar mati, de nada tem a ver com o que traz o texto.

Naquele idioma apenas topámos com três ou quatro sintagmas articulados: um é jangão tacur (jangan takut, "não tenhas medo"), frase que no capítulo 19 lhe diz o rei de Quedá ao vê-lo transido de pavor 
perante o espetro do gregoge. Outro é a primeira parte da frase que no capítulo 160 coloca nos lábios dos mendigos que pediam esmola à entrada do pagode de Tinagoogó, no Calaminhão (o que corresponde aparentemente ao reino dos Laos): minta dremá, xixapurha param, "dá-me esmola por Deus, senão matar-me-ei", em que minta derma significa de facto em malaio "pedir esmola"; param pode representar o malaio parang, "parão, catana", mas xixapurha não faz sentido, pois a cousa que mais se lhe aproxima, sisa purba, significa, "restos antigos, vestígios primitivos". No capítulo 177 o autor põe na boca do Pate de Demak, assassinado por um pajem, a frase quita mate, que traduz por "ai que me matou"; de facto, tanto em malaio como em javanês, kita mati significa "nós morremos" (ou, com um plural majestático, "eu morro"). Finalmente no capítulo 205 o autor põe na boca de um punhado de achéns uma frase em malaio macarrónico, mate, mate, quita fadulee, que interpreta "matai-nos, matai-nos, que não nos dá nada disso"; na realidade mati não significa "matar" (que se diz bunuh) mas "morrer"; para o resto da frase fazer sentido falta uma negativa (enunciativa, tidak ou tak, ou proibitiva, jangan) já que fadhuli (empréstimo árabe em língua corrente geralmente pronunciado peduli ou perduli) significa "interessado, preocupado, atento"; teríamos então algo como: mati, mati, kita tak fadhuli, "morrer, morrer, não nos importa".

No capítulo 15 o autor dá-nos também corretamente o significado de um topónimo, real ou imaginado, com que diz haver topado no país dos Batas, em Samatra: Batorrendão, que interpreta "pedra frita". Batu significa efectivamente "pedra", e rendang significa aproximadamente "frigir" - pois designa a operação culinária que consiste em cozer carne em leite de coco até este secar, o que implica uma espécie de fritura, já que, desidratado o líquido pela ebolição, resta a gordura, que como que frege o manjar. Assim no capítulo 50, onde nos fala do "morro de Pulo Hinhor, ilha dos cocos", que é, de feito, o significado do malaio Pulau Nyiur. Assim também no capítulo seguinte, em que explica correctamente a expressão quiay necodá (kiai nakhoda ou nakoda) como "senhor capitão", embora o apelativo de cortesia kiai ou kiyahi se use mais para mestres religiosos que para capitães de navios ou outros ricos burgueses,

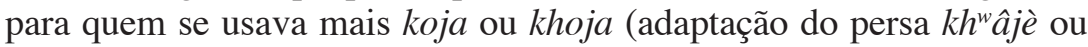
$k h^{w} \hat{a j} a$ ) ou em certos casos tuan, "senhor". Algumas vezes confunde-se, como sucede no capítulo 14, onde dá o bendara (do malaio bendahara, "espécie de primeiro ministro dos sultões malaios, tesoureiro") de Malaca, sob o regímen português, como chefe dos mouros da cidade em vez de capitão e justiça-mor dos gentios da cidade. 
Seja como for, como se poderá ver pela lista de palavras de origem malaia que damos em seguida, Fernão Mendes Pinto conhecia pelo menos uma boas dezenas de vocábulos nessa língua. $\mathrm{O}$ contraste com outros idiomas salta à vista, pois nesses casos, salvo raras excepções, os termos que emprega ou são comuns a mais autores, o que mostra terem penetrado em maior ou menor grau no indo-português, ou são termos forjados que não correspondem a nada em qualquer língua conhecida. Dir-se-ia, nalguns casos, que Fernão Mendes Pinto pretende reproduzir a consonância do concanim, a língua de Goa, que deve ter ouvido bastas vezes durante a sua permanência naquela cidade, sem embargo de praticamente a não referir na Peregrinação. Tal é nomeadamente o caso de uma frase que põe na boca dos monges que oficiavam no pagode de Tinagoogó: pautixorou numilem forandaché vaticur apolem, o que em nossa língua significaria "abranda, Senhor, a pena dos mortos, para que te louvem com sono quieto". A frase não corresponde a nada que possa ter significado; mas as terminações são muito comuns em concanim: -em é a desinência normal do caso reto singular dos nomes neutros de tipo temático (tipo kallo, kalli, kallem, "niger, nigra, nigrum"); -aché é terminação do caso reto do masculino plural dos adjetivos genitivais de qualquer declinação (razaché cheddé, "os criados do rei”), quase idêntica à do caso oblíquo do feminino singular dos mesmos adjectivos (razachê havelê, "no paço do rei"); e -olem é a terminação do caso reto da forma neutra singular de numerosos particípios (aslolem, "que fôra", chintlolem, "que pensara", kelolem, "que está feito", etc.).

É também da Índia que provém pelo menos o primeiro elemento da alcunha por que no Pegu era conhecido Gonçalo Falcão: Crisna $P a c a u$, a que Fernão Mendes atribui a significação fantasiosa de "flor das flores"; na realidade Crisna, i. e., Krșna, nome de um dos avatares de Vixnu, significa etimológicamente "negro" ou "azul-escuro" e nada tem a ver com flores.

Estes exemplos mostram bem a diferença entre o grau de conhecimento que Fernão Mendes Pinto teria do concanim e o que tinha do malaio, sem dúvida a língua asiática de que possuía mais luzes.

Destas se poderá avaliar pela lista que se segue, em que recenseamos todos os nomes comuns, topónimos e antopónimos da Peregrinação que nos parecem poder constituir, no todo ou em parte, empréstimos malaios. Deixamos de fora os termos de uso corrente em ásio-português, como junco, amouco, sumbaia ou zumbaia, pico (medida de peso), ganta, cate, tael, maz, cundorim, pucho, cacho, etc., que ocorrem em outros autores e Monsenhor Sebastião Rodolfo Dalgado explica corretamente 
no seu Glossário Luso-Asiático ${ }^{8}$; e bem assim os topónimos mais correntes, ainda que de origem malaia, cuja identificação poderá o leitor facilmente achar no Glossário Toponímico da Antiga Historiografia Portuguesa Ultramarina do Visconde da Lagoa ou nas anotações de Armando Cortesão à sua edição da Suma Oriental de Tomé Pires.

Alaradim (cap. 203) - gralha por Alauadim, nome tanto do sultão de Achém ('Alâ'ul-Dîn Ri'âyat Shâh al-Qahhâr, r. ca. 1539-1571) como do de Johor ('Alâu'l-Dîn Ri'âyat Shâh, r. 1528-1564) ao tempo de F. M. P. O nominativo árabe "Alâu'l-Dîn ("excelência da religião") é transcrito de diversas formas, mais ou menos acomodadas à fonética do idioma, em malaio: Ala'l-Din, Alauddin, Alaudin, etc.

alcá (cap. 158), nome uma moeda ou peso de ouro do Calaminhão, no valor de doze cruzados - em malaio alkah, empréstimo árabe de emprego raro, existe, mas significa "sangue cogulado" ou, como termo de direito, "domínio eminente sobre um baldio"; laku, "ato, comportamento, conduta" ou, como adjetivo, "válido, legal", que Dalgado aventa como étimo, não corresponde nem ao sentido nem à forma empregue pelo nosso autor.

Anchepisão, ilhotas de (cap. 23) - talvez < ancak, "açafate, tabuleiro de fibras entrançadas para oferendas" + pisang, "banana, bananeira".

Apefingau, ilhéu de (cap. 18) - talvez api, "fogo, lume" + ? (N. B.: o fonema $f$ é estranho ao malaio).

balão (passim) - balang, perahu balang, "sampana, pequena embarcação à vela com dois mastros".

Bata (cap. 13 \& ss.) - Batak, etnia do norte de Samatra.

Batampina, topónimo (passim) - batang, "vara, tronco, pé" + pinang, "areca, arequeira"; mas F. M. P. traduz por "frol do peixe" o que faz pouco sentido, e na realidade se diria bunga ikan ou kembang ikan.

Batobasoi, rio de (cap. 90) - < batu, "pedra" + besi, "ferro" ? ou basah" "molhado, -a"?

${ }^{8}$ Note-se que ao tempo em que Dalgado compôs o seu Glossário o malaio se escrevia ainda, as mais das vezes, em caracteres arábicos, e que foi de um dicionário malaio em tais caracteres que o autor se serviu; a sua transcrição não coincide portanto com a éjaan baru, que se não usava ainda, transcrevendo o $k$ final por $q$, nem sempre distinguindo conforme ao uso moderno os timbres das vogais ( $o$ e $u, e$ e $i, e$ mudo, dito e pepet, e $a$ ), assinalando com o makron as vogais supostamente longas (na realidade as vogais das sílabas abertas, visto não haver nas vogais malaias distinção de quantidade), etc.

Faculdade de Letras | Universidade de Coimbra 
Batorrendão, lugar de (cap. 15) - batu, "pedra" + rendang, "cozido e frito em leite de coco"; F. M. P. traduz por "pedra frita".

Batu Quirim, ponta de (cap. 32) - batu, "pedra" + kering, "seco, $-a "$.

Biaia Sora filho de Seribiaia Pracama de Raja (cap. 203), nome do sultão do Achém (Acéh) - se tomarmos Biaia como gralha por Riaia (trancrição aproximada de Ri'âyat), a expressão faz grosso modo sentido, já que o sultão do Achém era à época 'Alâu' l-Dîn Ri'âyat Shâh al-Qahhâr (r. ca. 1539-1571) - filho, porém, não de Biaia Sora ou Riaia Sora, mas de 'Alî Muhayat Shâh (r. ? - 1530), e pai de 'Alî Ri'âyat Shâh (r. 1571-1579). Quanto a seri, vide siri; Pracama de Raja (cf. de Raja) pode ser gralha por Pratama de Raja, i. e., Pertama Adiraja, "primeiro grão-senhor" (do sct pratama âdirâja, mesmo sentido).

bichara (cap. 52) - bicara, "consulta, deliberação" (< sct vicâra, mesmo sentido).

Bintor, vila das Ilhas Léquias ou Riu-kiu (cap. 142) - quiçá < bintur, "cacifo" ou < bentur, "colisão". Seja como for, a consonância do topónimo não parece compatível com a estrutura fonética do japonês em que cada sílaba se compõe de uma consoante e uma vogal unicamente (Bintoro, contudo, seria possível).

Brala de Quiai Adocá, templo do deus do trovão no Pegu berhala, "ídolo" e por extensão "templo idolátrico, pagode" + kiai, "senhor" + aduhai "sensacional, extraordinário, terrível" (?); na realidade "trovão" diz-se halilintar.

Bralapisão, templo de (cap. 39) - aparentemente < berhala, "ídolo" + pisang, "banana, bananeira".

Buaquirim, povoação de (cap. 39 \& 44) - buah "fruto " + kering, "seco".

Buatendoo, casa de (cap. 81) - talvez < buah, "fruto" + tanduk, "corno"; pisang tanduk é o nome de certa qualidade de bananas.

caciz moulana (cap. 178), título de um dignitário muçulmano de Java - caciz, no sentido de "mestre de religião muçulmana" é um antigo termo português de origem árabe, atestado desde as crónicas de Zurara, conquanto em árabe qasîs (correspondente ao siríaco qashish, "presbítero, ancião") designe um padre cristão e não um ulamá, alfaqui ou quejando mestre da lei islâmica; moulana, como adiantámos já, é termo arábico que passou tanto ao malaio como ao persa e ao hindustânico, que significa "nosso mestre" (maulâ, da raiz waliya, "estar próximo", apelativo usado para os mestres espirituais, em especial os das confrarias

Faculdade de Letras | Universidade de Coimbra 
sufis - de onde mulá, bastas vezes erroneamente grafado mullah com o sufixo possessivo -nâ, que indica a $1^{\mathrm{a}}$ pessoa do plural).

Cagirendão, monte (cap. 13) - kaji, nome de um peixe marinho (Plectorynchus spp.) + rendang "cozido e frito em leite de coco".

caladigão, "tribunal" (cap. 103) - quiçá de kalah, "queixar-se" + adegan, "acto, cena" (?).

Caleipute, lugar da Tartária (cap. 126) - talvez < kaleng, "calaím, ferro estanhado, lata" + putih, "branco".

Calemplui, ilha de (cap. 69 \& ss.) - talvez < kaleng, "lata, ferro estanhado, calaim" + ?

Calindão, baía de (cap. 72) - talvez < kelindung, da $\sqrt{ }$ lindung, "proteger, abrigar", com o prefixo apassivante, hoje obsoleto, ke-; ou < kelindan, "fio fiado, argadilho, dobadoira" e também "ajudante de condutor".

Campalaraja (cap. 163), nome do cais principal da capital do Calaminhão - talvez, por metátese, < pangkalan raja, "cais del-rei, cais real".

Campalarau, povoação de (cap. 34) - provavelmente gralha por Campalaran < kampung ou kampong, "aldeia" + larang, "defeso, proibido".

Campalator, cais de - kampung, "aldeia, bairro" + latur (ou lator), "ampola, empola, bolha".

Çapetu de Raja, nome de um mouro lução (cap. 28) - talvez < sepatu, "sapato" + adiraja, título de nobreza malaia.

caquesseitão (cap. 14) - nome de um grande palmípede carnívoro de Samatra, provavelmente fabuloso: lit. "pés do diabo" < kaki, "pé(s)" + Seitan, "Satanás".

Catamás (cap. 158), nome de uma cidade do Calaminhão sem dúvida < ketam mas ou ketam emas, "caranguejo de ouro" (e não "camarão de ouro" como diz o autor).

caubesi (cap. 95) - kayu, "pau" + besi, "ferro", como o autor diz correctamente; o nome aplica-se normalmente ao Euxideroxylon zwageri, Teijsm. \& Binnend., da família das Lauráceas.

charana (cap. 182), "malga, taça" - < cerana (< sct caraṇa), espécie de bandeja com pé, para bétele.

Cochins (passim) - habitantes da Cochinchina, termo que ao tempo designava o Tonquim < Kauci Cina ou Koci Cina, "Cochim da China", para distinguir da cidade de Cochim na Índia dita Koci Kolam, "Cochim de Coulão". No primeiro caso Kauci ou Koci < cantonês Kau Chi, mandarim Chiao Chih, vietnamita Giao-chì, antigo nome do Vietname. 
Coge Geinel (cap. 35) - khoja, "coge, coja (q. v.)" + zain-al... "adorno de..." (ar.), elemento de alguns nomes próprios como zain al'abidîn, "adorno dos adoradores [de Deus]" e zain-ad-dîn, "adorno da religião".

coge ou coja (passim) - khoja ou koja, do persa $k h^{w} \hat{a j e ̀ ~ o u ~} k h^{w} \hat{a j a}$, título dado aos burgueses ricos.

Coge Terão (cap. 185), nome de um capitão mogol que comandava um forte no Sião - < koja (vide "Coge ou Coja") + talvez terang, "claro, límpido, sincero".

Coretumbaga, rio de (cap. 96) - talvez gralha por Çonetembaga, que transcreveria sungai tembaga "rio do cobre", significado que o autor lhe atribui; F. M. P. transcreve, porém, geralmente sungai, "rio" por sumhe (em que o $m$ não deve ser articulado, representando meramente a nasalização da vogal precedente).

de Raja (passim) - título de nobreza malaia posposto a um nome próprio < diraja, abreviação de adiraja (< sct âdi, "inicial, principal" + râja, "rei"; epíteto de Manu, o Adão da mitologia hindu).

gerozemo (cap. 85) - talvez < juru azan, "almuadém" (lit. "encarregado da chamada"); mas o significado que F. M. P. atribui ao termo é inteiramente diferente, pois di-lo equivalente a "juiz da relação".

gigauho, "semi-homem silvestre, espécie de fauno" (cap. 73, 103, etc.) - quiçá de gigau (variante de igau ou ingau), "delírio, pesadelo; sonhar de alto" (?).

gregoge (cap. 19) - "suplício que consiste em serrar às postas um condenado" < gergaji, "serra, serrote".

Guateanguim, porto de (cap. 14) - talvez < kuat, "forte, sólido, resistente" (forma verbal, da mesma raiz menguati, "forçar, violentar, opor-se a, resistir a") + angin, "vento", ou então de watu, variante de batu, "pedra" + angin, "vento".

guedé (cap. 98) - tipo de embarcação; mas gedé (termo malaio de origem javanesa) significa simplesmente "grande".

Guijai Parão, nome do filho del-rei da Pérsia (cap. 120) - talvez < kiai, "senhor" + perang, "guerra"; o rei da Pérsia, como F. M. Pinto diz acertadamente noutro passo (cap. 124), era à época Shâh Tahmasp (r. 1524-1576).

Hicanduré, rio de (cap. 14 \& 173) - ikan, "peixe" + duri, "peixe marinho dos géneros Durius e Ketengus", F. M. P. dá este nome a dois rios distintos, um no País dos Batas, em Samatra Norte, outro em Java.

janga (cap. 92) - talvez gralha por juanga, q. v. 
Jantana (passim) - F. M. P. escreve geralmente “... do Jantana” por "de Ujantana" < ujung tanah, "extremidade da terra", i. e., o extremo sul da Península de Malaca, ou seja, o reino de Johor; o termo ocorre também em Diogo do Couto e outros escritores coevos.

jão (cap. 95) - segundo o autor medida de distância usada na China, equivalente a 4,5 léguas; talvez < jauh, "longe", conquanto o uso do termo como medida não esteja atestado alhures.

jatemar, produto inidentificado das ilhas Léquias (cap. 143) aparentemente < jati, "teca" + ?, quiçá mérah, "vermelho".

juanga (cap. 32) - "tipo de navio de guerra, usado sobretudo em Maluco"; certamente < juangan, substantivo derivado da $\sqrt{ }$ juang ou joang, "lutar, combater".

jurubaça, "intérprete" (passim, v. g. cap. 136 \& 140, passados no Japão) - de juru, "perito" + bahasa, "língua". É termo corrente na documentação luso-oriental.

jurupango (passim) - jerubung, jerumbung ou jubung, "cobertura, espécie de tenda armada a meio de um parau"; em F. M. P. designa um barco dotado de tal engenho mais que o engenho em si.

lacasá (passim) - F. M. P. traduz por "cem mil", que é o significado do étimo sanscrítico do termo (laks $a$ ), que por intermédio das línguas neo-áricas do norte da Índia dá a forma mais corrente em ásio-português, laque, por vezes leque, "cem mil"; mas em malaio moderno significa "dez mil".

lanchara (passim) - lancaran, perahu lancaran, nome de um

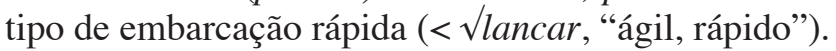

lanteá (passim) - tipo de embarcação; certamente < lantaian, "dotado de estrado, com coberta", derivado de lantai, "estrado, plataforma", embora os dicionários apenas registem a forma perlantaian, de sentido colectivo, "palco, estrado para dança".

laque xemena (cap. 32) - laksamana, "almirante, capitão-mor do mar" (do nome próprio sct Lakśmana, um dos herois do Râmâyana, transformado em título no sultanado de Malaca).

loias (cap. 22) - "manilhas, braceletes", talvez < loyang, "latão; molde, fôrma".

Lunçor (cap. 167), lugar do Calaminhão - talvez < longsor ou lungsur, "desprendimento de terras, escorregamento de terrenos".

Mampolacota, cidade de (cap. 46, etc.) - talvez de mempelam, "manga, mangueira" (senão, < do nome de outras plantas, como mempelu, "Nauclea junghuhnii, Merr." ou mempulur "Randia anisophylla, Hook.") + kota (termo de origem dravídica que passou 
também ao sct e a numerosas línguas da Índia e do Sueste Asiático) "forte, fortaleza, cidadela, cidade".

Manicatarão, pinhal de (cap. 117) - talvez < manikam, "joia" + terang, "claro, luminoso".

Minhaçumbá, rio de (cap. 28) - < minyak, "óleo" + sumba, "corante" ou "bambu espinhoso"; senão, < sembah, "inclinação, adoração, reverência, sumbaia, salamaleque".

Minhacutem, topónimo (cap. 88) - talvez < minyak, "óleo" + koteng, "só, isolado".

Minhagaru, estreito de (cap. 19) - minyak, "óleo" + gaharu, "águila, calambac, essência extraída do lenho-aloés, Aquilaria malaccensis, Lam.”.

minhamundi (cap. 174 \& 178), óleo de - provavelmente gralha por minhamundu < minyak, "óleo" + mundu, nome vulgar da Garcinia dulcis, Kurz.

Minhatolei, baía de (cap. 14) - < minyak, "óleo" + ?

Mongiloto, "advogado, procurador" (cap. 98) - talvez < menjelot, "saliente"; menjelut, "doente, enfadado, descontente" faz ainda menos sentido, mas o étimo chinês proposto por Dalgado não nos parece verosímil.

Muhé Lacasá, nome de uma divindade da China (cap. 110) - ? +laksa, "dez mil".

Mutipinão, porto de (cap. 47) - talvez < mutia ou mutiara, "pérola" + pinang, "areca, arequeira".

muxiparão ou muchiparam, "tesouro dos mortos" (cap. 109) de ? + parang, "parão, catana, faca de mato" ? ou + perang, "guerra"?

Nancá (cap. 92), figura mítica da China - talvez < nangka, "jaca, jaqueira".

Nhai , título de rainhas princesas, etc., na China, na Birmânia, etc. (cap. 111, 150, etc.) - <nyai, por vezes ainda usado como apelativo de cortesia para senhoras velhas e damas respeitáveis, embora hoje mais comum no sentido de "amante, concubina".

Nhai Camisana, nome da mãe del-rei da China (cap. 111) $<$ nyai + talvez khamis, "quinta-feira", por vezes usado como nome próprio de pessoas nascidas nessa dia.

Nhai Pombaia (cap.172), nome da emissária enviada pelo rei de Demak ao de Sunda - talvez < nyai (vide nhai) + pembayan "cunhada" (termo dialetal de Menancabo).

Nobi (passim) - epíteto de Mafamede; F. M. P. escreve normalmente "profeta Nobi", mas Nabi ou Al-Nabi, termo usurpado pelo malaio ao 
árabe, significa simplesmente "profeta", embora os muçulmanos o apliquem por antonomásia a Mafamede.

palinguindão, nome de um instrumento de guerra (cap. 118) - < perlindungan, "proteção" (?).

panaricão (cap. 175), designação de certos chefes, espécie de título de nobreza em Java - foneticamente é possível a derivação <

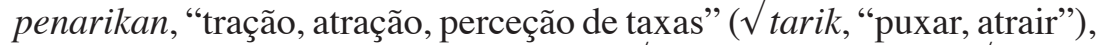
mas faz pouco sentido; o ambifixo pen- $\sqrt{ }-a n$, em malaio, pan- $\sqrt{ }$-an em javanês forma nomina actionis, sendo os nomina agentis formados simplesmente pelo prefixo pen- (em javanês pan-). Dalgado dá como étimo panjirakan, a que atribui o significado de "capitão colega", mas não achamos tal termo em nenhum dicionário. Não é impossível que se trate de corruptela do javanês panjenengan (< jeneng, "nome", portanto, lit. "renome, nomeada"), "estatuto, posição estabelecida, autoridade", usado em kråmå inggil (linguagem de alta cortesia) como substituto da segunda pessoa do singular, mais ou menos equivalente a " $\mathrm{V}$ a $\mathrm{Ex}^{\mathrm{a}}$ ".

Pangueirão de Pate (cap.173 \& ss.), título do "imperador" ou rei principal da Java - < pangéran, "príncipe" + adipati, "senhor principal" (cf. de Pate).

panoura (passim) - nome quer F. M. P. tanto a um tipo de embarcação, semelhante à fusta e à galeota, como às espadas presas aos dentes dos elefantes de guerra; talvez < penawar(an), "antídoto, defesa, remédio" ( $\sqrt{ }$ tawar, "neutralizar, tornar inócuo ou ineficaz"); ou então < penawanan, "captura" ( $\sqrt{ }$ tawan, "capturar, prender").

Passarvão (cap. 172 \& ss.) - má transcrição nas edições modernas da Peregrinação de Passaruão na edição original, transcrição de Pasuruan, nome de um porto da Java sito a $7^{\circ} 42^{\prime} \mathrm{S}$, $112^{\circ}$ 57' E.

passeivão (cap. 18 \& 173) - "dependência de uma palácio real", < paséban, peséban, pasiban ou pesiban, "sala de audiências", $(\sqrt{ }$ séba, "recepção, audiência") termo de origem sanscrítica, usado sobretudo em Java.

Pate (passim) - pate em português parece representar dois termos distintos: patih, (do sânscrito pati, "senhor", excepcionalmente com a desinência do nominativo, $-s$ ou $-h$ ), título dado aos vizires ou primeiros-ministros dos reis da Java, e bupati (do sânscrito bhû, "terra" + pati, "senhor"), título dado aos regentes ou governadores provinciais; F. M. P. (cap. 174) dá-o por equivalente a "duque".

Pate Benão, antropónimo (cap. 72) - pate (q. v.) + benão, que tanto pode representar benang, "fio, linha de coser", como um termo homónimo que significa "alforreca". 
Patedecão (cap. 163), nome de um mandarim do Calaminhão pate (cf. Pate Benão) + dekan, "ratazana"; ou então < Decão, (< persa Dekhân, hindustânico Dakhin < sct dakșina, "mão direita, sul"), nome genérico da Índia meridional e, em especial, do planalto do interior da Península.

Penacão, nome de um baluarte (cap. 16) - talvez < penakan, kemanakan ou keponakan, "sobrinho".

peretanda, "homem a cavalo com bandeira que precede o governador, espécie de sota ou arauto" (cap. 106, 140, 141, etc.) talvez < pertanda, forma prefixada de tanda, "sinal, indicação", com praticamente a mesma significação.

Permata Gundal, antropónimo (cap. 66) - talvez < permata, "jóia, gema, pedra preciosa" + gundal, "marca, sinal" ou gundul, "calvo".

Pisamanes, (cap. 179), nome de um lugar de Java $-<$ pisang, "banana" + manis, "doce".

Pisanduré, ilha de (cap. 144) - talvez < pisang, "banana" + duri, "espinhoso, -a".

poitão, produto inidentificado das ilhas Léquias (cap. 143) quiçá < penghitam, "enegrecedor, que serve para tingir de negro".

Pomiserai, aldeia de (cap. 171) - talvez < ? + serai, "citronela, chá-príncipe, Cymbopogon citratus, (DC) Stapf".

Pongatur, cidade da Cochinchina, o actual Tonquim (cap. 131) - talvez < pengatur, "organizador, coordenador" (nomen agentis da $\sqrt{ }$ atur, "dispor, organizar"). As cidades de Lingator e Baguetor, mencionadas no mesmo capítulo têm terminação idêntica, mas o sentido do seu primeiro elemento não se deixa adivinhar.

Pongor, cidade do Japão (cap. 139) - sem dúvida de Punggur, nome de um lugar da Península malaia, um pouco ao sul de Malaca, onde morreu D. Paulo da Gama, celebrizado num syair malaio (poema em quadras rimadas), citado por Diogo do Couto ( Tratado dos Gamas, e Ásia, IV, viii, 11, p. 281): "Cappitam dom Paulo, baparan, depugor agandia, malu, sita, taundor", ou seja: Kapitan dom Paulo / berperang di Punggur / enggan dia malu / setapak tak undur, o que vertido em português significa literalmente: "O capitão D. Paulo / teve batalha em Pungor / não quis ele passar vergonha / um palmo não recuou".

puchisucões (cap. 72) - suposto nome chinês de certos peixes espinhosos que o autor descreve em pormenor; pucuk significa em malaio "ponta" e, com diversos qualificativos, entra nos nomes de diversos peixes: ikan pucuk ("peixe de pontas") é o Trichiurus savala, ao passo que por pucuk pisang se entende o Labeobarbus faciatus, e

Faculdade de Letras | Universidade de Coimbra 
ikan pucuk nipah designa a moreia (Murcenesox cinereus, Forsk), etc.); quanto ao $2^{\circ}$ elemento, sucão, $c f$. "sucão de Pointir".

pulo (passim) - pulau, "ilha".

Pulo Botum (cap. 20) - pulau, "ilha" + butun ou butung, "Barringtonia asiatica, Kurz".

Pulo Cambim, rio de (cap. 39) ou (cap. 220) ilha de - na realidade "ilha (pulau) das cabras (kambing)".

Pulo Camude, ilha a sul de Martabão (cap. 147, 153, etc.) pulau, "ilha" + kemudi, "leme".

Pulo Capás, ilha de (cap. 42) - "ilha (pulau) do algodão (kapas)".

Pulo Catão, ilha de (cap. 46 \& 183) - provavelmente "ilha (pulau) dos caranguejos de água doce (katam)".

Pulo Champeiló (cap. 42, 220 \& 221) - conquanto a mesma forma ocorra noutros autores da época, parece gralha por Pulo Champedó, ou melhor, Pulo Champedá, i. e. Pulau Cempedak, "ilha do champadá (Artocarpus champeden, Spreng, ou A. polyphema, Pers., espécie de jaqueira)".

Pulo Hinhor, morro de, na Ilha dos Cocos (cap. 50, 66, 67, 145147) - pulau, "ilha" + nyiur, "coco, coqueiro". F. M. P. dá o nome de Pulo Hinhor a uma ilha do mar da China e a outra da costa da Baixa Birmânia.

Pulo Pracelar, nome de uma ilha no estreito de Malaca (cap. 144) - pulau significa "ilha", mas o resto do topónimo permanece inidentificável, não é invenção de F. M. P. pois aparece também no roteiro de João de Lisboa e, aparentemente, na carta dita de Cantino, na forma arabizada Fulo Falsolar.

Pulo Quenim (cap. 20) - talvez < pulau, "ilha" + kening, "sobrancelha".

Pulo Quirim, ilha de (cap. 55) - "ilha (pulau) seca (kering)".

Pulo Sambilão, ilhas de (cap. 144, 146) - trata-se, como o nome indica, de um arquipélago de nove (sembilan) pequenas ilhas, sitas na parte setentrional do estreito de Malaca; "ilha chamada Sambilão" (cap. 146) é uma maneira imprópria de dizer.

Pulo Tiquos (cap. 20) - "ilha dos ratos" < pulau, "ilha" + tikus, "rato".

Puxanguim, nome de uma cidade da Tartária (cap. 126) - talvez < pusa, "força" + angin, "vento".

Quai Colompom, nome de uma divindade da China (cap. 110) kiai + kelumpang, "satirão (Sterculia foetida, L.)" (?). 
Quanjiparu, cidade da Cochinchina, actual Tonquim (cap. 132) quiçá < kanji, termo de origem dravídica significando "goma, amido" + paruh, "bico" (?); ou < kancing, "botão, campaínha, aldraba de porta" + paroh ou paruh, "metade" (?).

Quãojeparu, minas de (cap. 61) - talvez < kancing, "botão", ou $<$ kanji "amido, goma" + paruh, "bico, ponta"; é visivelmente a mesma palavra que Quanjiparu.

Quiai (passim) - kiai, "mestre, senhor (título dado sobretudo aos mestres religiosos)".

Quiai Brazagarão (cap. 190), antropónimo no Pegu $-<$ quiai (q. v.), talvez + beras, "arroz" + garam, "sal" (cf. bergaram, "com sal, salgado").

Quiai Figrau, "deus dos átomos do sol" (cap. 110) - kiai + ?

Quiai Hucombinor (cap. 13) - deus da justiça dos Batas < Kiai, "Mestre, Senhor" + hukum, "justiça" + talvez bin Nur, "filho da luz" em arábico.

Quiai Hujão, "deus da chuva" na China (cap. 110) - kiai, "senhor" + hujan, "chuva".

Quiai Mitru, nome de uma divindade da China (cap. 110) - kiai + mitra, "amigo, companheiro" (?).

quiai necodá (cap. 51) - kiai, "senhor, mestre" (vide quiai) + nakhoda ou nakoda (do persa nâv khodâ ou nâ khodâ, lit. "deus da nau, deus do navio") "capitão".

Quiai Nivandel, "deus das batalhas do campo Vitau" (cap. 110, 149 , etc.) - kiai + ?

Quiai Panaricão (cap. 174), antropónimo - aparentemente < kiai + panaricão, q. v.

Quiai Panjão (cap. 56 \& ss.), antropónimo $-<$ kiai, "mestre, senhor" + panjang, "longo, comprido".

Quiai Varatel (cap. 90) - < kiai (vide quiai) + ?; F. M. P. atribuilhe o significado de "rei de todos os peixes do mar", o que em malaio se diria raja segala ikan laut.

Quilem, ribeira de (cap. 16) - talvez < kilang, "moínho, azenha, lagar, trapiche, engenho".

Raja Dato (cap. 6) - raja, "rei" + datuk, "ancião, chefe".

Rajahitau, antropónimo (cap. 39) - talvez gralha por Raja Hitam, "rei negro".

Rate na Quem Dau (cap. 178), termo que segundo F. M. P. significaria em todo o Extremo Oriente "pestana do mundo" - < ratna (do sct, forma idêntica), "jóia" + ?.

Faculdade de Letras | Universidade de Coimbra 
Rendacalem, cidade da Tartária (cap. 126) - talvez < rendah, "baixo, curto" + kaleng, "calaím, ferro estanhado, lata"; mas a ordem das palavras em malaio seria inversa, pois o determinado precede sempre o determinante.

saligue (cap. 22) - "paus tostados e ervados com peçonha" < seligi, "lança, azagaia".

sangue-de-pate (cap. 175), título de nobraza em Java e ilhas vizinhas - forma paronímica que representa sang adipati $<$ sang, artigo de cortesia (como el em português el-rei) + adipati "senhor principal" (cf. de Pate).

Seri Bilaia Quendou Pracamá de Raja (cap. 31) - título atribuído ao sultão de Johor < seri (vide siri) + wilaya ou wilayat "região, distrito, província" (ar.) + ? + pertama, "primeiro" + adiraja (vide de Raja). Prakâma existe em sct com o sentido de "cousa agradável", mas não consta que tenha passado às línguas modernas do Sueste Asiático.

seró, (cap. 153 \& ss.) - seria, segundo F. M. P., o nome de certo tipo de embarcação da Birmânia e regiões contíguas; mas em malaio o termo séro significa "almadrava". Os possíveis étimos aventados por Dalgado não nos parecem aceitáveis.

Singapamor, nome de um lago da Tartária (cap. 128 \& 182) e de um outro do Sião, "comummente chamado 'lago de Chianmai' (i.e. de Chieng Mai)" - < singa, "leão" + pamor, "glória".

siri (passim) - Seri, título de nobreza (< sct Çrî,, "próspero, auspicioso, feliz").

sitá, sitá (cap. 213), segundo F. M. P., “já, já, já” - embora a cena se passe no Japão parece transcrever o malaio sudah, sudah, que, de facto, significa "já, já".

sucão de Pontir (cap. 57) - happax de F. M. P.: Pontir não corresponde a nenhum lugar conhecido e o título de sucão tampouco. Sokong, "suporte, esteio", parece não fazer sentido aqui. A explicação aventada por Dalgado (suku, "tribo, etnia, suco" + hang, antigo título de nobreza, abreviação de hulubalang, "ourobalão") não é possível, já que a ordem gramatical requerida pela gramática malaia seria a inversa, * hang suku. Pode quando muito tratar-se de gralha por sarão, atestado noutros textos, < serang, "arrais, mestre de equipagem" (do persa sar, "cabeça, chefe" + hang, "grupo, turma, equipa").

Sumbor, ilhéu de (cap. 55, 57, 60, etc.) - < sumber, "fonte, nascente de água".

Sumehitam, rio de (cap. 38) - "rio (sungai) negro (hitam)". 
Sumhepadão, rio de (cap. 71) - sungai, "rio" + padang, "campo, terra, terreno, plaino".

Susoquerim, cidade de (cap. 79) - susu, "leite, mama, teta" + kering, "seco, -a"; senão < susuh, "espinho" ou < susuk, "cavilha".

Tanamedil, topónimo (cap. 74) - talvez < tanah, "terra, país" + medil, variante de bedil, "arma de fogo".

Tanauquir, rio de (cap. 45) - tanah, "terra, país" + ukir, "escultura" (?).

Tilaumera, morro de (cap. 47) - talvez < telau, "malhado, manchado" + mérah, "vermelho".

Tranocem Mudeliar, antropónimo (cap. 90) - certamente gralha por Tuan Ocem Mudeliar, i. e., Tuan, "senhor" + Husain, antropónimo + Mudaliar, termo de origem dravídica (tâmule mudaliyâr, plural honorífico de mudali) que significa "cabeça, cabo, chefe" e pode ser posposto a um nome próprio como título.

tucão (passim) - tukang, "mestre, mestre de um navio, obreiro, artífice especializado".

Turbão, lugar de (cap. 15) - talvez < terbang, "voar".

Ucunchinirat (cap. 184), nome de uma princesa do Sião - talvez $<$ ? + javanês ningrat, "nobre, fidalgo, aristocrata".

xinanguibaleu, "prisão dos degradados condenados a trabalhar na construção da Grande Muralha" (cap. 108) - de ? + balai, "bailéu, varanda, sala de audiência" (?). 